$\mathbb{P}$ periodica polytechnica

Mechanical Engineering $51 / 1(2007) 33+38$

doi: 10.3311/pp.me.2007-1.05 web: http://www.pp.bme.hu/me

(c) Periodica Polytechnica 2007

RESEARCH ARTICLE

\section{Contributions of different factors to the} improvement of the creep rupture strength of creep resistant martensitic steels

\author{
Yousef Elarbi / Béla Palotás
}

Received 2007-03-14

\begin{abstract}
Boilers, pipes, and turbine components of fossil power generating plants are expected to be exposed to steam at increased temperature and pressure to improve power generating efficiency. This trend requires high $\mathrm{Cr}$ creep resistant martensitic steels having higher creep rupture strength (CRS) than Modified 9 Cr-1Mo steel. The aim of this paper is to overview different factors that improve the creep rupture strength of these required new steels. The addition of $\mathrm{W}, \mathrm{B}, \mathrm{Co}, \mathrm{Cu}$ and other elements to the 9-12\% Cr steels which has been studied by many researches to improve CRS is explained. Improvement of the method of heat treatment that has been investigated by other investigators is introduced as well. It has been reported that CRS can be raised by optimizing the normalizing temperature, controlling the cooling rate from normalization temperature before tempering, or by applying the thermo-mechanical control process (TMCP). By the application of TMCP process, a great increase in the CRS can be obtained.
\end{abstract}

\section{Keywords}

CRS $\cdot$ Creep resistant steels $\cdot$ alloying elements $\cdot$ Heat treatment $\cdot$ Precipitation-hardening

\section{Yousef Elarbi}

Department of Materials Science and Engineering BME, H-1111 Budapest, Bertalan L. u. 7., Hungary

e-mail: binyusef@yahoo.com

\section{Béla Palotás}

Department of Materials Science and Engineering BME, H-1111 Budapest, Bertalan L. u. 7., Hungary

e-mail: palotasb@eik.bme.hu

\section{Introduction}

Creep resistant steels are mainly used in power generating and petrochemical plants. All product forms are included. Large forgings and castings are used to build turbines, whereas tubes, pipes, plates and fittings are the typical products for application in pressure vessels, boilers and piping systems. In addition to high creep strength other material properties are also important, e.g. hardenability, corrosion resistance and weldability. The importance of such properties depends on the specific application. For example, good hardenability is very important for steels used for large turbine rotors, whereas good weldability is a prerequisite for an application in power plant tubing and piping [1]. Although the different demands from application are reflected by differences in chemical composition, all product forms use the same mechanisms to improve creep strength.

An increase in the thermal efficiency of power plants can be most effectively achieved by increasing the temperature and, to a lesser extent, the pressure of the steam entering the turbine. The most modern steam power stations now in operation reach efficiencies to around $42 \%$ with steam temperatures of $600{ }^{\circ} \mathrm{C}$ and pressures of 250-300 bars. The next generation of steam power plants should be able to operate with steam at $625-650$ ${ }^{\circ} \mathrm{C}$, to increase thermal efficiencies to around $45 \%$. Of course, the increasing operating temperatures and pressures impose increasingly stringent requirements on the materials of the construction. Improvement of the creep rupture strength of these steels is one of these requirements [2].

\section{Strengthening Mechanisms}

The high $\mathrm{Cr}$ ferritic steel contains several types of obstacles to dislocation motion. They are sub-boundaries, free dislocations within subgrains, and $\mathrm{M}_{23} \mathrm{C}_{6}, \mathrm{Fe}_{2} \mathrm{M}$ and $\mathrm{MX}$ particles [3]. Solute atoms such as Mo and $\mathrm{W}$ can also contribute to the creep strength. The strengthening mechanisms attributed to these obstacles are classified into the following three categories:

1 Dislocation hardening: sub-boundaries and free dislocations.

2 Particle hardening: $\mathrm{M}_{23} \mathrm{C}_{6}$ and $\mathrm{Fe}_{2} \mathrm{M}$ on sub-boundaries and $\mathrm{MX}$ within the subgrains. 
3 Solution hardening: $\mathrm{W}$ and Mo in solution.

The most potential strengthening mechanisms operating at high temperature service in low alloy and chromium modified steels are precipitation strengthening and solid solution strengthening as the effect of the dislocation strengthening is usually limited to short time.

\section{Precipitation Strengthening}

When assessing how the dispersion of the secondary phases affects the creep properties of the steel, we must take into account not only the dispersion characteristic ascertained immediately after heat treatment, but also their changes caused either by coarsening of the particles or by precipitation of new particles during creep [4]. The best measure of the dispersion of particles has proved to be their mean interparticle spacing $(L)$ which can be calculated as:

$$
L=\frac{1}{2 \cdot \sqrt{N_{v} \cdot d}}-d \cdot \sqrt{\frac{2}{3}}
$$

where $N_{v}$ is the number of particles per unit volume, and $d$ is the mean particle diameter.

\section{Contributions of Alloying Elements to the CRS of Creep Resistant Steels}

\subsection{Boron and Nitrogen}

El-kashif and his co-authors [5], investigated the behavior of boron and its effect on creep strength and microstructure of $9 \mathrm{Cr}-$ $3 \mathrm{~W}-3 \mathrm{Co}$ heat resistant steel that contained 0.02 and $0.05 \% \mathrm{~N}$. As it is shown in Figs. 1, 2, they concluded that for as-received steels, increasing the $\mathrm{B}$ content in $0.05 \% \mathrm{~N}$ steels shows remarkably lower creep rupture strength. On the other hand, they found that the increasing $\mathrm{B}$ content in $0.02 \% \mathrm{~N}$ steels shows higher creep strengths.

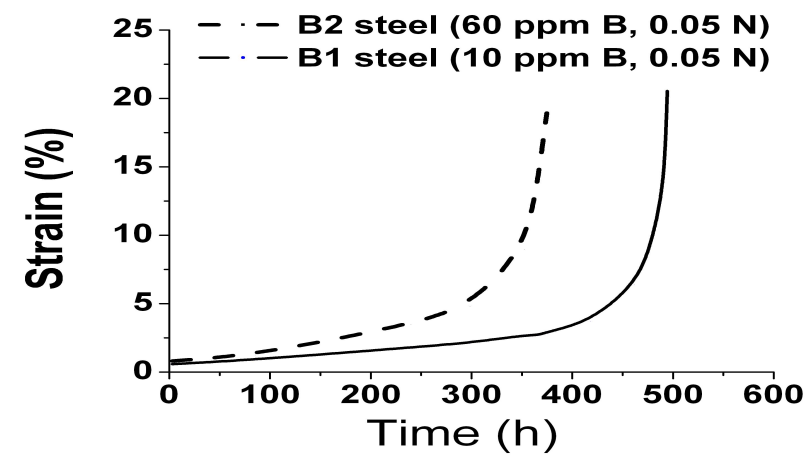

Fig. 1. Creep curves for boiler steels $\mathrm{B} 1(0.001 \% \mathrm{~B}) \mathrm{B} 2(0.005 \% \mathrm{~B})$ containing $0.05 \% \mathrm{~N}[5$

They also observed that when fixing the $\mathrm{N}$ content at $0.02 \%$ for rotor steels (B3, B4, and B4-2), the creep life increases by increasing the $\mathrm{B}$ content, but in case of boiler steels there is a limited increase in the creep strength as a result of controlled heat treatment where they applied lower tempering temperature for these steels, Fig. 3 shows these observations.

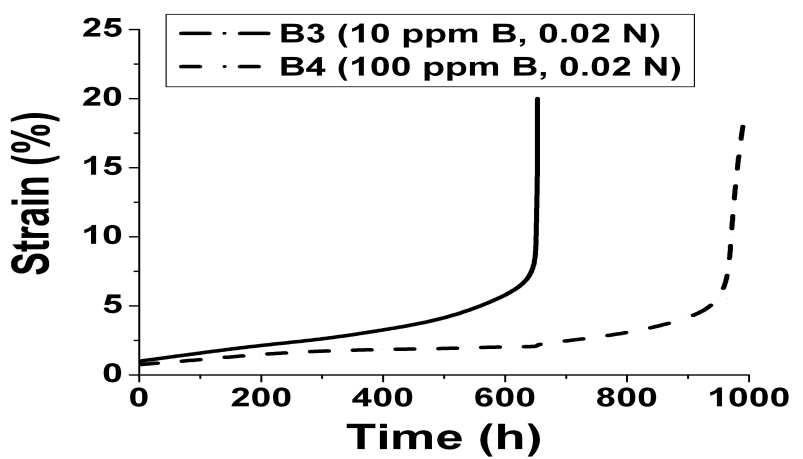

Fig. 2. Creep curves for boiler steels $\mathrm{B} 1(0.001 \% \mathrm{~B}) \mathrm{B} 2(0.005 \% \mathrm{~B})$ containing $0.02 \% \mathrm{~N}[5]$

In their micrographic investigations using ATE, they also observed that much free $\mathrm{B}$ exists in the matrix of the low $\mathrm{N}$-high B steel of which creep strength is the highest. Therefore, free $\mathrm{B}$ in solid solution is more effective on the stabilization of microstructure and strengthening than $\mathrm{B}$ contained in precipitates, namely $\mathrm{M}_{23} \mathrm{C}_{6}$ carbides. This investigation concluded also that boron in steels of a suitable content of $\mathrm{N}$ is adequate to enhance creep strength by increasing the amount and the stability of fine precipitates such as $\mathrm{VN}$ and dislocation microstructure.

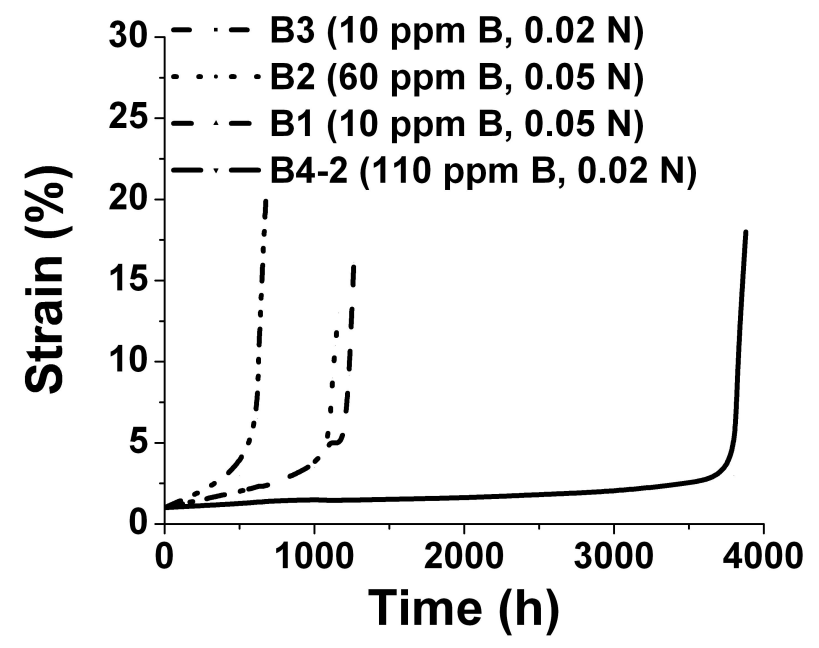

Fig. 3. Creep curves of controlled heat-treated boiler and rotor steels [5]

The controlled addition of B to high $\mathrm{Cr}$ heat resistant steels was studied by Toshiaki Horiuchi and his co-workers [6] and their results were as follows:

1 Boron shifts the transition from the transient to the acceleration creep to longer times, resulting in a great decrease in minimum creep rate and hence longer creep lives.

2 Boron improves microstructural stability in the vicinity of grain boundaries through the stabilization of $\mathrm{M}_{23} \mathrm{C}_{6}$ carbides and suppresses the coarsening by enriching $\mathrm{B}$ into them.

This study included the investigation of the effect of hightemperature normalizing on the creep strength where it was found that the creep rate for the $0.0092 \mathrm{~B}-\mathrm{H}$ steel $(\mathrm{H}$ designates the high temperature normalizing condition) reaches almost the same value as the $0.0139 \mathrm{~B}$ steel at the stress of $80 \mathrm{MPa}$. 
Another study was carried out to investigate the boron distribution in creep resistant steels [7] where they found that boron was well distributed in almost all the precipitated phases like $\mathrm{M}_{23} \mathrm{C}_{6}, \mathrm{M}_{6} \mathrm{C}$, MX and Laves phases in both as-received and crept conditions of the investigated steel. During this study, thermodynamic calculations on this alloy system were also performed and they showed that the addition of boron may influence the nucleation rate of boron-rich phases during pretempering condition and thereby promote the formation of fine distribution of $\mathrm{M}_{23} \mathrm{C}_{6}$ carbides.

Boron addition has a positive effect [8] on the tempering processes of steels due to two factors:

i Promoting the precipitation of $\mathrm{M}_{23} \mathrm{C}_{6}$.

ii Suppressing transformation and stabilizing the tempered martensite against austenitizing.

\subsection{Cobalt}

The effect of adding Co on the microstructure of $9 \% \mathrm{Cr}$ ferritic steels was studied in order to explain the drastic difference in creep properties between $3 \%$ Co and Co free steels [9]. It was concluded that;

1 Finer and heterogeneous microstructure with $\delta$-ferrite was clearly found in Co free steel while typical homogeneous tempered martensitic structure was obtained in $3 \%$ Co steel.

2 It was found that inter-metallic compounds tended to precipitate at the boundaries between $\delta$-ferrite and surrounding martensitic regions even at tempering stage.

3 It was concluded that superior creep properties of $3 \%$ Co steel compared to Co free one is due to the suppressing of $\delta$-ferrite as it is shown in Fig. 4 below.

\subsection{Tungsten}

Many researches were carried out to investigate the effect of $\mathrm{W}$ on the creep strength of $9-12 \% \mathrm{Cr}$ ferritic steels. One of these was performed by Yutaka Tsuchida and his co-authors [10], in which three grades of $9 \% \mathrm{Cr}$ steels were investigated. One steel did not contain $\mathrm{W}$, the second was alloyed with 0.7 $\% \mathrm{~W}$ and the third alloyed with $1.7 \% \mathrm{~W}$. The effects of $\mathrm{W}$ on the properties of the investigated steels can be summarized as follows:

1 The CRS increases linearly with $\mathrm{W}$ addition as it is indicated in Fig. 5

2 As shown in Fig. 6, the hardness remained almost unaffected during creep tests, indicating that the improvement of CRS is not attributed to the fine precipitation or clustering.

3 The addition of $\mathrm{W}$ enhances the partition of $\mathrm{Nb}$ into $\mathrm{VN}$, and causes the increase of the lattice constant of $\mathrm{VN}$.
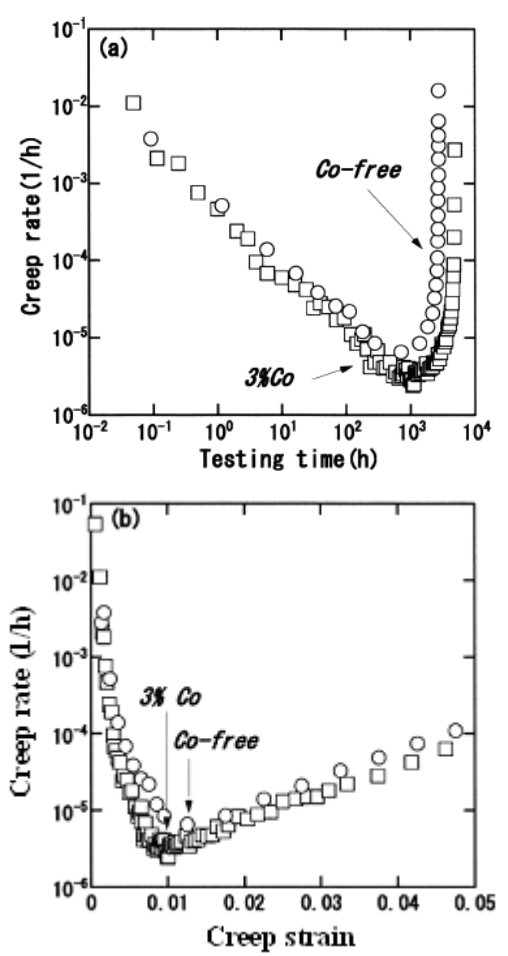

Fig. 4. Comparison in creep properties between $3 \%$ Co and Co free steels at $650{ }^{\circ} \mathrm{C} / 120 \mathrm{Mpa}$. (a) creep rate-time curves in logarithmic plots and (b) creep rate-creep strain curves [9]

$4 \mathrm{~W}$ addition increases $\mathrm{CRS}$ at $600{ }^{\circ} \mathrm{C}$ for 1000 hours at a rate of $35 \mathrm{MPa} / 1 \% \mathrm{~W}$. About one-half of the increase is due to the enhanced solution of $\mathrm{Nb}$ into $\mathrm{VN}$, the remaining half is considered to be due to the restraint of subgrain growth by film-like Laves phase along the grain boundary and subgrain boundary.

Weldments of the $\mathrm{W}$ containing steel P122 (11Cr-0.4Mo$2 \mathrm{~W}-\mathrm{V}-\mathrm{Nb}-\mathrm{Cu}$ ) were investigated by Nobuyoshi Komai and Fujimitsu Masuyama [11]. They pointed out that the test specimens of the weldments of this investigated steel crept at 650 and $675^{\circ} \mathrm{C}$, and ruptured in the fine grained HAZ (referred as type IV failure). This has shown that these weldments were weaker in creep strength than the base metal. They also recognized that there was a decrease in hardness of the HAZ of these weldments with creep damage.

\section{Effect of Heat Treatment on the Creep Strength of High Cr-Steels}

Katsumi Yamada and his co-workers [12] investigated three types of ferritic steels that were heat treated in two ways, normalized \& tempered (NT), and quenched \& tempered (QT). They found that dominant precipitation behavior changed with cooling rate from normalization temperature before tempering and better creep properties have been obtained in the steels quenched than in the air-cooled ones as it is indicated in Figs. 7 and 8 .

It is confirmed that precipitation of $\mathrm{M}_{23} \mathrm{C}_{6}$ is suppressed and total fraction of MX is relatively increased by the quenching procedure. It is thought that the better creep resistance is mainly 


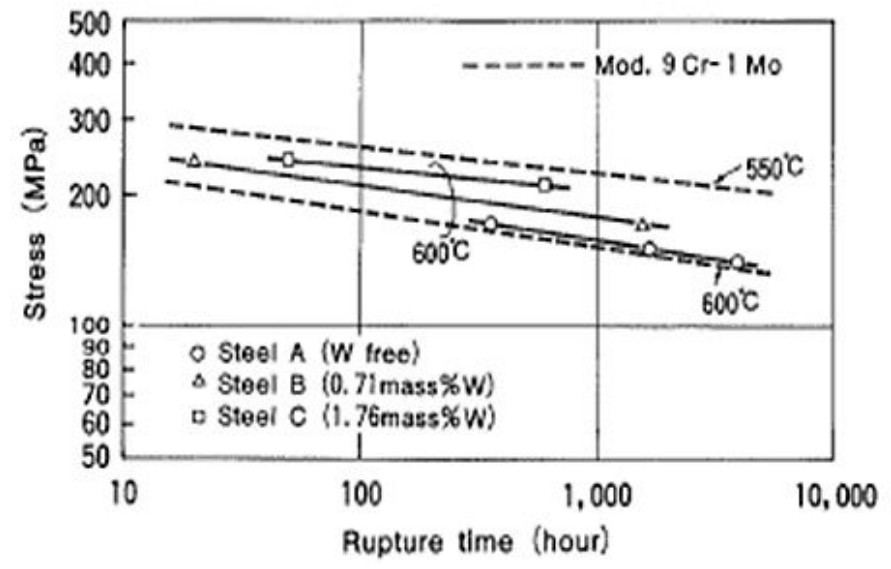

Fig. 5. The relationship between stress and time to rupture of the three steels [10]

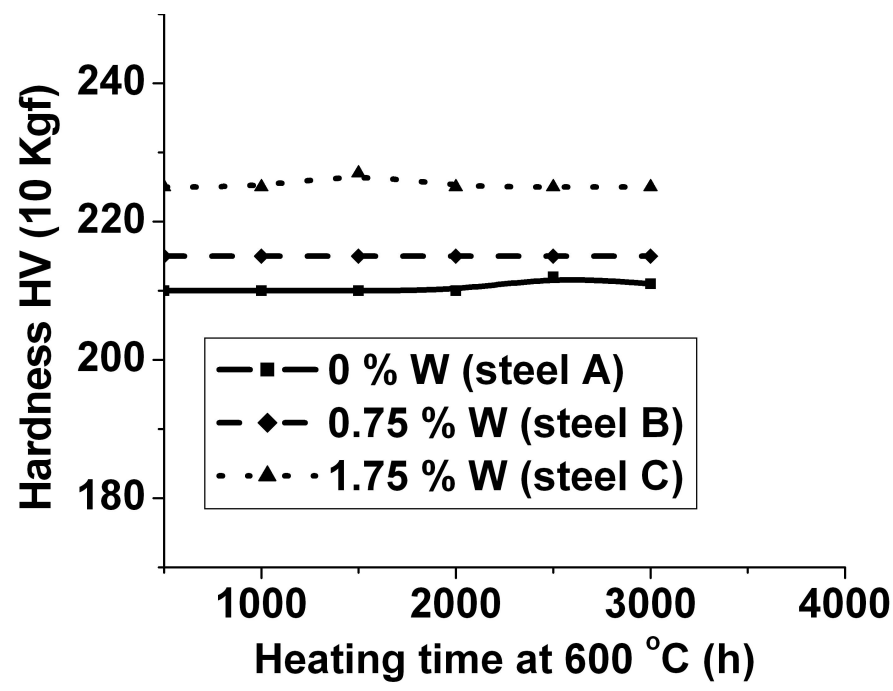

Fig. 6. Hardness change in the head of the creep ruptured specimens [10]

due to fine distribution of MX that is achieved by suppressing typical co-precipitation of $\mathrm{MX}$ such as $\mathrm{Nb}(\mathrm{C}, \mathrm{N})-\mathrm{VN}$ during cooling after normalization and tempering.

\section{Effect of Thermo-Mechanical Control Process on CRS of High Cr Steels}

The application of this process (TMCP) on 9Cr-lMo-V-Nb$\mathrm{N}$ heat resistant steel was studied by Yutaka Tsuchidak and his co-workers [13] to investigate the effect of the controlled heating $\left(\mathrm{T}_{S}\right)$ and final-rolling $\left(\mathrm{T}_{f}\right)$ temperatures of rolling process on the creep rupture strength of four TMCP steels and a fifth one that was unrolled normalized and tempered steel (designated NT). The results of this study are summarized as follows;

1 Raising $\mathrm{T}_{s}$ and lowering $\mathrm{T}_{f}$ improve the CRS in different ways. Raising $\mathrm{T}_{S}$ augments the coherency strain around $\mathrm{VN}$ precipitates through lattice expansion of $\mathrm{VN}$ due to the increased partition of $\mathrm{Nb}$ to $\mathrm{VN}$, and lowering $\mathrm{T}_{f}$ makes the $\mathrm{VN}$ disperse more finely by making dislocations preferential nucleation sites, resulting in improved CRS through decreased interprecipitate distance.

2 Successive rolling from a sufficiently high temperature is im-

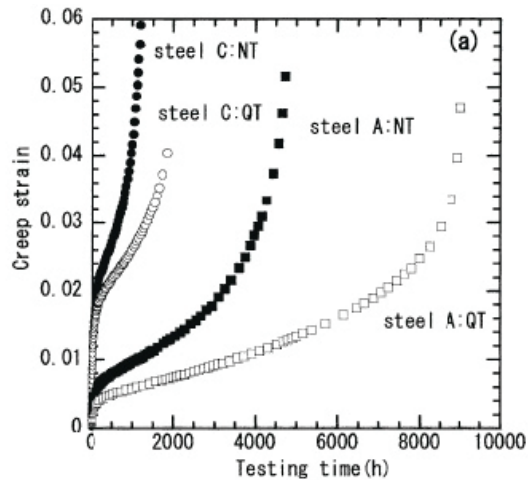

Fig. 7. Changes in creep strain with respect to time for NT and QT steels at $650^{\circ} \mathrm{C} / 120 \mathrm{MPa}$ [12]

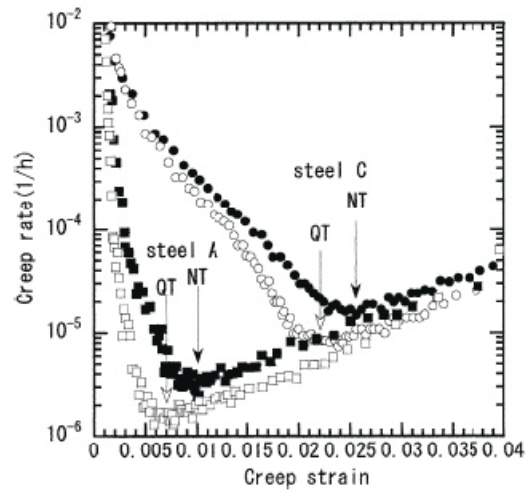

Fig. 8. Changes in creep rate with respect to strain for NT and QT steels at $650^{\circ} \mathrm{C} / 120 \mathrm{MPa}[12]$

portant to avoid coarse precipitation of $\mathrm{VN}$ and to exert precipitation hardening during tempering to its full extent. Figs. 9 and 10 show the stress-rupture time curves and the change of tensile and $0.2 \%$ proof strengths with final-rolling temperature of the studied steels.

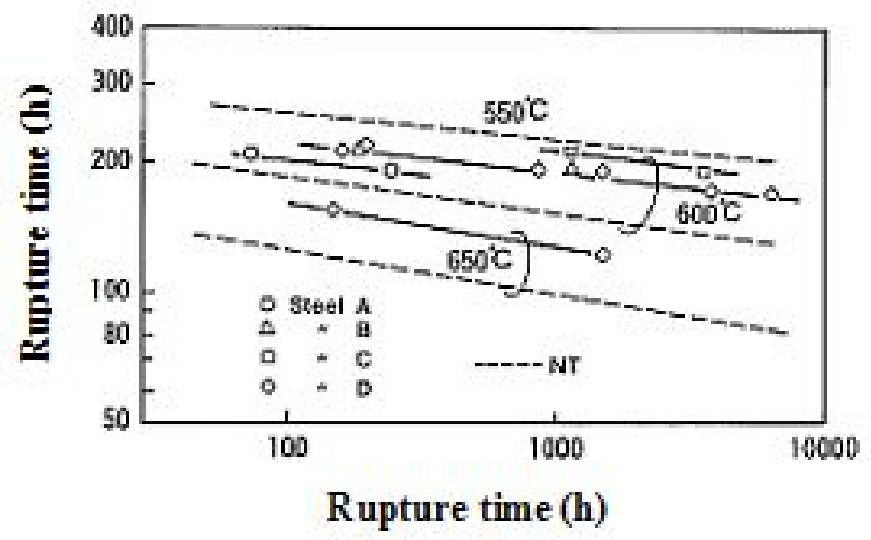

Fig. 9. The relation between stress and rupture time of the investigated steels [13]

\section{Concluded Remarks}

Many factors can contribute to the improvement of the creep rupture strength of heat resistant steels that are exposed to elevated temperatures in the power plants. These factors were investigated by many researchers in their practical studies in 


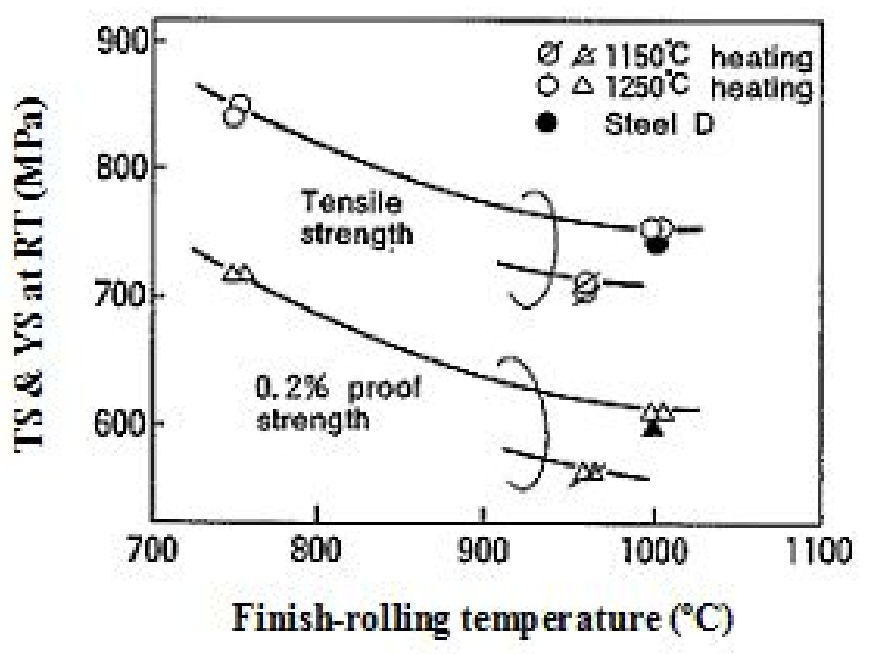

Fig. 10. The Change of tensile and $0.2 \%$ proof strengths with finish-rolling temperature of the investigated steels [13]

many countries and the conclusions of these investigations can be summarized as follows:

1 Out of many strengthening mechanisms in low and high chromium modified steels operated at high temperature service; the most potential mechanisms are precipitation strengthening and solid solution strengthening.

2 The increasing of the B content to low N-content steels (such as $0.02 \% \mathrm{~N}$ ) results higher creep strengths than those of higher $\mathrm{N}$-content ones. In this case it was reported that creep strength is enhanced through increasing the amount and the stability of fine precipitates such as VN, and dislocation microstructure. Boron shifts the transition from the transient to the acceleration creep to longer times, resulting in a great decrease in minimum creep rate and hence longer creep lives. Boron improves the microstructural stability in the vicinity of grain boundaries through the stabilization of $\mathrm{M}_{23} \mathrm{C}_{6}$ carbides and suppresses the coarsening by enriching $\mathrm{B}$ into them. Boron addition has a positive effect on the tempering processes of steels into two points; the first is promoting the precipitation of $\mathrm{M}_{23} \mathrm{C}_{6}$, and the second is suppressing transformation and stabilizing the tempered martensite against austenitizing.

3 Superior creep properties in Co-containing steels were obtained by suppressing $\delta$-ferrite compared to Co free steels. Typical homogeneous tempered martensitic structure was obtained in $3 \%$ Co steel.

4 With $\mathrm{W}$ addition to high $\mathrm{Cr}$ steels, the CRS increases while the hardness remains almost unaffected. The addition of $\mathrm{W}$ enhances the partition of $\mathrm{Nb}$ into VN. About one-half of the increase of CRS is due to the enhanced solution of $\mathrm{Nb}$ into VN. The remaining half is considered to be due to the restraint of subgrain growth by film-like Laves phase along the grain boundary and subgrain boundary. Weldments of the $\mathrm{W}$ containing steel P122 (11Cr-0.4Mo-2W-V-Nb-Cu) which were crept at 650 and $675^{\circ} \mathrm{C}$, ruptured in the fine grained HAZ (referred to as type IV failure), this has shown that these weldments were weaker in creep strength than the base metal. It was also recognized that there was a decrease in hardness of the HAZ of these weldments with creep damage.

5 Concerning the effect of heat treatment, better creep properties were reported to be obtained in the quenched steels than in the air-cooled ones. It is also confirmed that precipitation of $\mathrm{M}_{23} \mathrm{C}_{6}$ is suppressed and the total fraction of $\mathrm{MX}$ is relatively increased by the quenching procedure. It is thought that better creep resistance is mainly due to fine distribution of MX that is achieved by suppressing typical co-precipitation of $\mathrm{MX}$ such as $\mathrm{Nb}(\mathrm{C}, \mathrm{N})-\mathrm{VN}$ during cooling after normalization and tempering.

6 The creep rupture strength can be enhanced by controlling the heating $\left(\mathrm{T}_{S}\right)$ and finish-rolling $\left(\mathrm{T}_{f}\right)$ temperatures of rolling process of creep resistant steels, raising $\mathrm{T}_{S}$ augments the coherency strain around VN precipitates through lattice expansion of $\mathrm{VN}$ due to the increased partition of $\mathrm{Nb}$ to $\mathrm{VN}$, and lowering $\mathrm{T}_{f}$ results a finer dispersion of $\mathrm{VN}$ improving CRS by a decreased interprecipitate distance. Successive rolling from a sufficiently high temperature is important to avoid coarse precipitation of VN and to exert precipitation hardening during tempering to its full extent.

\section{References}

1 von Hagen I, Bendick W, Creep resistant ferritic steels for power plants, available at http://www.us.cbmm.com.br/english/sources/ techlib/science $\left\{_{-}\right\}$techno/table $\left\{_{-}\right\}$content/sub $\left\{_{-}\right\} 4 /$ images/ pdfs/040.pdf

2 Ennis PJ, Czyrska-Filemonowicz A, Recent advances in creep-resistant steels for power plant applications Creep resistant steels for power plant, OMMI 1 (April 2002), no. 1, available at http://www. ommi.co.uk/

3 Leffler B, Stainless steels and their properties, http://www. outokumpu. com/files/Group/HR/Documents/STAINLESS20.pdf Scientific report.

4 Foldyna V, Purmensky J, Zdenek Kubon, Development of advanced chromium steels with respect to microstructure and structural stability, ISIJ International 41 (2001), S81-S85. supplement.

5 El-kashif E, Asakura K, Shibata K, Effects of nitrogen in $9 \mathrm{Cr}-3 \mathrm{~W}-3 \mathrm{Co}$ ferritic heat resistant steels containing boron, ISIJ International 42 (2002), no. $12,1468-1476$.

6 Toshiaki Horiuchi, Masaaki Igarashi, Fujio ABE, lmproved Utilization of Added B in $9 \%$ Cr Heat-Resistant Steels Containing W, ISIJ International 42 (2002), S67-S71. supplement.

7 Hofer P, Miller MK, Babu SS, David SA, Cerjak H, Investigation of Boron Distribution in Martensitic $9 \%$ Cr Creep Resistant Steel, ISIJ International 42 (2002), S62-S66. supplement.

8 Kobayashi S, Toshimori K, Nakai K, Ohmori Y, Asahi H, Muraki T, Effects of Boron Addition on Tempering Processes in an Fe-9Cr-O.1C Alloy Martensite, ISIJ International 42 (2002), S72-S76. supplement.

9 Katsumi Yamada, Masaaki Igarashi, Seiichi Muneki, Fujio ABE, Effect of Co-addition on microstructure in high Cr ferritic steels, ISIJ International 43 (2003), no. 9, 1438-1443.

10 Yutaka Tsuchida, Kentaro Okamoto, Yoshikuni Tokunaga, Improvement of Creep Rupture Strength of High Cr Ferritic Steel by Addition of W, ISIJ International 35 (1995), no. 3, 317-323. 
11 Nobuyoshi Komai, Fujimitsu Masuyama, Microstructural Degradation of the HAZ in $11 \mathrm{Cr}-0.4 \mathrm{Mo}-2 \mathrm{~W}-\mathrm{V}-\mathrm{Nb}-\mathrm{Cu}$ Steel (P122) during Creep, ISIJ International 42 (2002), no. 12, 1364-1370.

12 Katsumi Yamada, Masaaki Igarashi, Seiichi Muneki, Fujio ABE, Effect of Heat Treatment on Precipitation Kinetics in High-Cr ferritic steels, ISIJ International 42 (2002), no. 7, 779-784.

13 Yutaka Tsuchidak, Kentaro Okamoto, Yoshikuni Tokunaga, Improvement of Creep Rupture Strength of 9Cr-1Mo-V-Nb-N Steel by ThermoMechanical Control Process, ISIJ International 35 (1995), no. 3, 309-316. 